\title{
Educação em saúde em um centro de saúde escola acerca da prevenção ao sarampo: um relato de experiência
}

\author{
Health education in a school health center about measles prevention: an experience \\ report
}

Educación sanitaria en un centro de salud escolar sobre prevención del sarampión: un informe de experiencia

Yury Gomes ${ }^{1 *}$, Angela Maria Rodrigues Ferreira ${ }^{1}$, Margarete Feio Boulhosa ${ }^{1}$, Lisiany Carneiro de Santana Moreira ${ }^{1}$, Remo Rodrigues Carneiro ${ }^{1}$, Lidiane Assunção de Vasconcelos ${ }^{1}$, Amanda Lorena Gomes Bentes ${ }^{1}$, Emily Manuelli Mendonça Sena ${ }^{1}$, Eduardo Martins Oliveira ${ }^{1}$, Jonas Gloria de Oliveira ${ }^{1}$.

\section{RESUMO}

Objetivo: relatar a experiência de acadêmicos de um curso de graduação em enfermagem acerca de uma atividade de educação em saúde sobre sarampo. Relato de experiência: Trata-se de um estudo tipo relato de experiência desenvolvido através da metodologia da problematização do Arco de Maguerez, a qual seguiu as etapas de observação da realidade, identificação dos pontos-chaves, teorização, hipótese de solução e retorna à realidade. A primeira etapa se deu na observação pelos alunos de usuários na sala de espera da vacinação em uma unidade de saúde. Os pontos-chaves deu-se pela discussão dos alunos acerca da procura das pessoas pela vacinação e suas inquietações. A teorização ocorreu pela busca de evidências científicas em bases de dados, manuais, normas e portarias. A intervenção foi uma atividade educativa em saúde sobre os aspectos mais importantes da doença, especialmente a prevenção, com a utilização de um cartaz e realização de atividade de fixação. Considerações finais: a experiência proporcionou aos discentes uma grande reflexão sobre a importância da educação em saúde, além da oportunidade de ter compartilhado saberes entre os usuários e os acadêmicos acerca de uma doença infectocontagiosa de grande relevância na saúde pública, enfatizando a vacina como a principal forma de prevenção.

Palavras-chave: Programa nacional de imunizações, Educação em saúde, Sarampo.

\begin{abstract}
Objective: to report the experience of undergraduate nursing students about a health education activity on measles. Experience report: This is an experience report type study developed through the problematization methodology of the Arco de Maguerez, followed by the steps of observing reality, identifying key points, theorizing, hypothesis of solution and returning to reality. The first step was the observation by students of users in the vaccination waiting room at a health unit. The key points came from the students' discussion about people's demand for vaccination and their concerns. Theorizing occurred by searching for scientific evidence in databases, manuals, standards and ordinances. The intervention was an educational health activity on the most important aspects of the disease, especially prevention, with the use of a poster and carrying out fixation activity. Final considerations: the experience provided students with a great reflection on the importance of health education, in addition to the opportunity to have shared knowledge between users and academics about an infectious disease of great relevance in public health, emphasizing the vaccine as the main form of prevention.
\end{abstract}

Keywords: National immunization program, Health education, Measles.

1 Universidade do Estado do Pará (UEPA), Belém - PA. *E-mail: Yury_yg@hotmail.com 


\section{RESUMEN}

Objetivo: informar sobre la experiencia de estudiantes universitarios de enfermería sobre una actividad de educación sanitaria sobre el sarampión. Informe de experiencia: Este es un estudio tipo informe de experiencia desarrollado a través de la metodología de problematización del Arco de Maguerez, seguido de los pasos de observar la realidad, identificar puntos clave, teorizar, hipótesis de solución y volver a la realidad. El primer paso fue la observación por parte de los estudiantes de los usuarios en la sala de espera de vacunación en una unidad de salud. Los puntos clave vinieron de la discusión de los estudiantes sobre la demanda de vacunación de las personas y sus preocupaciones. La teorización se produjo al buscar evidencia científica en bases de datos, manuales, normas y ordenanzas. La intervención fue una actividad educativa de salud sobre los aspectos más importantes de la enfermedad, especialmente la prevención, con el uso de un póster y la realización de actividades de fijación. Consideraciones finales: la experiencia proporcionó a los estudiantes una gran reflexión sobre la importancia de la educación para la salud, además de la oportunidad de compartir el conocimiento entre usuarios y académicos sobre una enfermedad infecciosa de gran relevancia en la salud pública, enfatizando la vacuna como el principal forma de prevención

Palabras clave: Programa nacional de inmunización, Educación para la salud, Sarampión.

\section{INTRODUÇÃO}

Com a promulgação da Constituição Federal de 1988 o estado brasileiro comprometeu-se a proporcionar aos seus cidadãos uma saúde gratuita e de qualidade por meio da Lei 8.080 que estabeleceu a criação do Sistema Único de Saúde (SUS) baseando-o em três princípios centrais: universalidade, equidade e integralidade (PAIM, 2018). A partir desse momento a definição de saúde no país, outrora centrado na ausência de doença, expandia-se de forma a englobar diversos conceitos que fomentariam a consolidação do SUS, como a prevenção e promoção a saúde (MACHADO MF, et al., 2015).

Diante disso, visando expandir as estratégias de prevenção de doenças, em virtude, principalmente, de graves problemas sanitários vivenciados com as epidemias de varíola e febre amarela no século XX, o Brasil desenvolveu o Programa Nacional de Imunizações (PNI), o qual tem como objetivo primordial coordenar as ações de imunização em todo o território nacional (LIMA AA e PINTO ES, 2017).

Nesse contexto, destaca-se o sarampo: uma das doenças infectocontagiosas de maior preocupação no mundo. Esta patologia possui grande poder de transmissibilidade, podendo uma pessoa doente infectar até outros dezenove indivíduos, com transmissibilidade por pessoa a pessoa, onde o vírus é expelido na respiração, fala, espirro ou tosse (XAVIER AR, et al., 2019).

Em 2016 o Brasil recebeu o certificado da Organização Mundial da Saúde (OMS) de erradicação do sarampo, no entanto, em março de 2019 foi registrado pela Secretária Estadual de Saúde do Pará casos de sarampo em três crianças e considerando que o surto no estado supracitado está relacionado ao do apresentado no estado de Roraima e Amazonas, iniciados em fevereiro de 2018, o Brasil passou a manter a transmissão da doença por mais de doze meses o que, infelizmente, resultou na perda da certificação de erradicação da doença no país (BRASIL, 2019).

Ressalta-se que a vacina ofertada pelo PNI, é a forma mais eficaz de prevenção de inúmeras doenças, principalmente o sarampo, sendo estas extremamente seguras ao estimularem o sistema imune a adquirir anticorpos contra a doença. Assim, os imunobiológicos quando adotados como estratégia em saúde pública são considerados como um dos melhores investimentos em saúde (BRASIL, 2020).

Em conformidade com tal, uma das estratégias mais eficazes de promoção e prevenção a saúde, aliada a vacinação, é a educação em saúde. Para Machado MF, et al. (2015), esta está ancorada no conceito de promoção da saúde, que trata de processos que abrangem a participação de toda a população no contexto de sua vida cotidiana e não apenas das pessoas sob risco de adoecer.

Assim, em virtude do exposto, o objetivo deste estudo é relatar a experiência de acadêmicos de um curso de graduação em Enfermagem de uma universidade pública na cidade de Belém- PA na realização de uma educação em saúde sobre a prevenção do sarampo em um centro de saúde escola. 


\section{RELATO DE EXPERIÊNCIA}

Este trabalho consiste em um estudo descritivo do tipo relato de experiência que busca relatar a vivência de acadêmicos do oitavo semestre do curso de graduação em Enfermagem em uma ação educativa sobre a prevenção do sarampo em um centro de saúde escola localizado na cidade de Belém do Pará durante as aulas práticas de dois componentes curriculares: gestão e gerencialmente em saúde e doenças infectoparasitárias no período de 27 de agosto a 11 de setembro de 2019.

Utilizou-se a metodologia da problematização do Arco de Maguerez. Esta metodologia é constituída de cinco etapas: $1^{\underline{a}}$ observação da realidade, $2^{\underline{a}}$ levantamento dos pontos - chaves, $3^{\underline{a}}$ teorização, $4^{\underline{a}}$ hipótese de solução e $5^{\text {a }}$ retorno a realidade (BERBEL N e GAMBOA S, 2012).

A primeira etapa do trabalho se deu com a observação da realidade pelos discentes da sala de espera para a vacinação no centro de saúde, onde observou-se o fluxo, o público majoritário, assim como, os imunobiológicos mais procurados. Após a observação os acadêmicos foram instruídos por suas preceptoras a comentarem o que lhes chamaram mais atenção.

Notou-se que a questão do sarampo foi bastante citada pelos acadêmicos durante suas observações, principalmente, sobre o conhecimento da população acerca da doença e suas principais formas de prevenção, levando em consideração, o aumento no número de casos da doença no estado no período.

Posteriormente, realizou-se a busca na literatura de artigos publicados sobre sarampo e o conhecimento das pessoas sobre a doença, principalmente, no que diz respeito a prevenção, nas bases de dados da Biblioteca Virtual em Saúde (BVS), Scientific Electronic Library Online (SciELO) e no mecanismo de busca Google Acadêmico, utilizando "sistema único de saúde", "programa nacional de imunização", "enfermagem", "educação em saúde" e "sarampo" como palavras-chaves.

Ademais, realizou-se uma visita técnica na secretária municipal de saúde (SESMA) da cidade de Belém do Pará e dialogou-se com os responsáveis pelo setor de imunização a fim de arrecadar mais informações sobre a cobertura vacinal contra o sarampo no município.

Como hipótese de solução definiu-se a criação de um cartaz sobre a doença, ressaltando, sobretudo, a sua forma de transmissão e a importância da vacinação. Para a apresentação e explanação do mesmo, ocorreu a realização de uma atividade de educação em saúde e um exercício de fixação onde foram elaboradas 5 perguntas para os usuários, sendo elas: " 1 - Apenas as crianças podem ser infectadas pelo sarampo?"; "2 - Se aparecer um caso suspeito de sarampo, levar essa pessoa imediatamente ao posto de saúde?"; "3 - Grávidas podem tomar a vacina contra o sarampo?"; "4 - Caso a pessoa tome uma dose adicional da vacina contra o sarampo, há risco para a saúde?"; "5 - Só pego sarampo se encostar em alguém com a doença?".

O cartaz abordava tópicos como: O que é a doença, forma de transmissão, sinais e sintomas e como prevenir, além de informações sobre o calendário vacinal e o manejo de indivíduos com caso suspeito de Sarampo. Assim, foram enfatizadas informações claras e objetivas, a fim proporcionar a fácil compreensão do leitor sem causar-Ihe exaustão durante a leitura.

Muitos usuários insinuaram que, apesar ter um conhecimento empírico sobre a doença, saberiam reconhece-la, principalmente, pelas "manchas avermelhadas na pele" e que sua primeira atitude ao lidar com alguém com esse sintoma seria ir direto a unidade de pronto atendimento. Poucos tinham conhecimento da forma de transmissão do vírus, assim como, o grande poder de contagio da doença.

Ao final do diálogo os acadêmicos propuseram um exercício de fixação. Foram repassados aos participantes duas plaquinhas: uma vermelha que significava "não" e uma verde que significava "sim" e realizaram-se cinco indagações, uma de cada vez sendo que cada indivíduo teria que levantar a placa verde caso achasse que a pergunta fosse verdadeira ou a plaquinha vermelha se a achasse errada.

O retorno a realidade, no dia da educação em saúde, se deu com a abordagem de 24 usuários na sala de espera da vacina do centro de saúde escola. Reforça-se que as atividades exercidas ocorreram em dois grupos de 12 pessoas para facilitar a comunicação assim como evitar a dispersão dos usuários. 


\section{DISCUSSÃO}

A enfermagem exerce um importante papel na comunidade ao executar ações de educação em saúde, seja em âmbito individual ou coletivo, e considerando que o enfermeiro é um educador é de extrema importância que já na graduação os alunos sejam inseridos em atividades educativas frisando a importância destas como uma das principais formas de promoção a saúde (GODOY LA, et al., 2018). Sendo assim, a atividade de educação em saúde apresentada neste trabalho mostrou-se de grande valia, não somente para os discentes, mas também para os indivíduos que aceitaram participar os quais foram extremamente receptivos com o grupo.

Primeiramente, os alunos convidaram todas as pessoas que estavam na sala de espera da vacina do centro de saúde escola para participar da atividade, organizou-se uma pequena roda entre os acadêmicos e o público aproximando as cadeiras e com todos sentados, mostrando que a equipe estava ali para dividir seus conhecimentos e não impô-los, assim como, receptivos aos saberes de cada um ali presente. Isso mostra que o trabalho de grupos de educação em saúde favorece o aprimoramento de todos os indivíduos, não apenas no aspecto social como também no profissional, por meio da valorização de diversos saberes e da possibilidade de intervir criativamente no processo saúde-doença (BRAGA EP, 2013).

Havia uma grande pluralidade de pessoas participando, majoritariamente mulheres com seus filhos, essencialmente, mães com seus bebês no colo, homens adultos, adolescentes e idosos. Cada pessoa do grupo apresentou-se e foi explanado o que seria realizado e sobre o que. Ao início perguntou-se o que as pessoas sabiam sobre o sarampo. Muitas responderam que já tinham ouvido falar na televisão e/ou já tinham sido contaminada ou conheciam alguém que já tinha "pegado". Alguns idosos afirmaram que na sua época de juventude era normal crianças apresentarem a doença.

Essa situação é muito relatada na comunidade científica no sentindo de que o sarampo, em momentos passados, foi considerado como uma das doenças da quadra infantil, quando muitas crianças eram acometidas pelo vírus. E isso é muito preocupante pois para Xavier AR, et al. (2015) banalizar a doença é extremamente errôneo uma vez que a cada 1.000 crianças com sarampo 1 pode desenvolver complicações como encefalite, convulsões, pneumonia e podem evoluir a óbito.

Para auxilio da atividade foi utilizado um cartaz para ilustrar as informações que os discentes estavam repassando, o qual continha informações curtas e de fácil compreensão, além de imagens coloridas e de grande facilidade de fixação por parte do leitor. Ressalta-se que a produção de materiais educativos é pertinente em ações de educação em saúde, visto que é compreendido como uma estratégia facilitadora do aprendizado, ao observar a mudança de atitudes e enriquecimento de informações do público-alvo (PAIVA A e VARGAS E, 2015).

A primeira pergunta foi "Apenas as crianças podem ser infectadas pelo sarampo?". Dos 24 participantes, $22(91,6 \%)$ responderam "não", ou seja, tinham conhecimento de que o vírus também pode acometer adultos. Destaca-se que a gravidade da enfermidade em adultos e adolescentes é mais elevada, ocasionando complicação como traqueobronquite, miocardite e diarreia, porém, em crianças menores de um ano, principalmente desnutridas, é fator relevante de óbito (FERNANDES CC, et al.,2020).

A próxima indagação foi "Se aparecer um caso suspeito de sarampo leva-lo diretamente a unidade de saúde?" onde apenas $8(33,3 \%)$ responderam corretamente, que não se deve levar o paciente a unidade de saúde. Recomenda-se o acionamento da equipe de saúde para atendimento domiciliar pois é extremamente relevante que este paciente evite sair em público devido o grande por de transmissibilidade do vírus e se caso seja essencial ir a uma unidade de saúde deve-se utilizar máscara de proteção cirúrgica ou N95. É relevante frisar que 0 isolamento deve ser mantido até 4 dias após o período exantemático e em indivíduos imunossuprimidos deve ser mantido até a completa resolução da doença (BRASIL, 2019).

O terceiro questionamento foi "Grávidas podem tomar a vacina contra sarampo?" onde 14 (58,3\%) indivíduos responderam corretamente "não". Isso se dá pelo fato de a vacina ser proveniente de vírus atenuado, enfraquecido, e se associada a gestação, a qual deixa o sistema imunológico da mulher mais vulnerável, a probabilidade de a grávida manifestar a doença e complicações é acentuada (MEDEIROS EA, 2020). 
A quarta pergunta "Caso uma pessoa tome uma dose adicional do imunobiológico, há risco para a saúde?" onde 18 (75\%) usuários responderam corretamente "não". É importante frisar que aos 12 meses de idade deve ser administrada a vacina tríplice viral, a qual protege contra caxumba, rubéola e sarampo, e aos 15 meses deve ser feita uma dose da vacina tetra viral, contra sarampo, rubéola, caxumba e varicela, a qual pode ser realizada até os 23 meses e 29 dias de idade. Caso não ocorra todo esse esquema vacinal corretamente os indivíduos de 20 a 49 anos de idade sem comprovação de vacinação anterior é recomendado uma dose do tríplice viral. Destaca-se que pessoas as quais já manifestaram a doença com a devida confirmação médica já são considerados imunizados (BRASIL, 2020).

E a quinta e última pergunta foi "Só se contamina com a doença se encostar em alguém com vírus?" a qual $23(95,8 \%)$ participantes responderam de forma correta "não" mostrando que houve fixação de que o vírus é transmitido de pessoa a pessoa sem necessitar de contato direto (XAVIER A, et al.,2019).

Observou-se a adesão dos usuários às informações repassadas, evidenciada por meio da participação deles ao fazerem perguntas sobre o assunto e dialogar com os acadêmicos acerca da temática. Sendo assim, nota-se que a utilização de estratégias de Educação em Saúde como esta contribui para o esclarecimento da população, disseminação de saberes assim como os faz adquirir conhecimentos acerca da doença e principalmente da vacina e sua importância.

\section{REFERÊNCIAS}

1. BRASIL. Ministério da Saúde. Princípios do SUS. Brasília, 2020. Disponível em: https://www.saude.gov.br/sistemaunico-de-saude/principios-do-sus. Acesso em: 31 maio. 2020.

2. BRASIL. Ministério da Saúde. Programa Nacional de Imunização. Brasília, 2020. Disponível em: https://www.saude.gov.br/saude-de-a-z/vacinacao/sobre-o-programa. Acesso em: 31 maio. 2020.

3. BRASIL. Ministério da Saúde. Vacinação de rotina. Brasília, 2020. Disponível em: https://www.saude.gov.br/oministro/924-saude-de-a-a-z/caxumba/13984-vacinacao-caxumba. Acesso em: 06 jun. 2020.

4. BRASIL. Ministério da Saúde. Situação do Sarampo no Brasil. Brasília, 2019. Disponível em: https://www.saude.gov.br/images/pdf/2019/janeiro/28/Informe-Sarampo-n36-24jan19aed.pdf . Acesso em: 01 jun. 2020.

5. BRASIL. Ministério da Saúde. Fluxograma de atendimento do sarampo. Brasília, 2019. Disponível em: http://189.28.128.100/dab/docs/portaldab/documentos/fluxograma_atendimento_sarampo.pdf. Acesso em: 05 de jun. 2020.

6. BERBEL N, GAMBOA S. A metodologia da problematização com o arco Maguerez: uma reflexão teóricoepistemológica. Filosofia e educação, 2012; 3(2): 264-287.

7. BRAGA EP. A importância dos grupos de educação em saúde na atenção básica/estratégia saúde da família. Monografia (Especialização em atenção básica em saúde da família) - Faculdade de medicina, núcleo de educação em saúde coletiva. Universidade Federal de Minas Gerais, Brumadinho, 2013; 70p.

8. FERNANDES CC, et al. Manifestações clínicas do sarampo com ênfase na faixa etária infantil. Brazilian Journal of realth Review, 2020; 3(2): 3033-3036.

9. GODOY LA, et al. A enfermagem no despertar populacional frente ao compromisso com a imunização. Revista Científica Univiçosa, 2018; 10(1): 949-954.

10. LIMA AA, PINTO ES. O contexto histórico da implantação do Programa Nacional de Imunização (PNI) e sua importância para o Sistema Único de Saúde (SUS). Scire Salutis, 2017; 7(1): 53-62.

11. MEDEIROS EA. Entendendo o ressurgimento e o controle do sarampo no Brasil. Acta Paul Enferm, 2020; 33(1): 14.

12. MACHADO MF, et al. Integralidade, formação de saúde, educação em saúde e as propostas do SUS - uma revisão conceitual. Ciência e saúde coletiva, 2015; 12(2): 335-341.

13. PAIM JS. Sistema único de saúde (SUS) aos 30 anos. Ciência e saúde coletiva, 2018; 23(6): 1723-1728.

14. PAIVA A, VARGAS $E$. Os Materiais Educativos e seus públicos: um panorama a partir da literatura sobre o tema. $X$ Encontro Nacional de Pesquisa em Educação em Ciências - X ENPEC, 2015.

15. MACHADO MF, et al. Integralidade, formação de saúde, educação em saúde e as propostas do SUS - uma revisão conceitual. Ciência e saúde coletiva, 2015; 12(2): 335-341.

16. XAVIER AR, et al. Diagnóstico clínico, laboratorial e profilático do sarampo no Brasil. Jornal brasileiro de patologia médica e laboratorial, 2019; 55(4): 396-401. 